\title{
The Groundedness of Negative Truths
}

\author{
Naoaki KITAMURA*
}

\begin{abstract}
According to some philosophers, (1) if truthmaker theory is true, then all truths have truthmakers, but (2) there are no truthmakers for negative truthstherefore, the theory is false. In this paper, I defend truthmaker theory by arguing against both claims. I begin by examining and rejecting a recent attempt to argue against (1). I then present my own argument against (1) by considering the connection between truthmaking and the more general notion of grounding. Finally, I critically examine the proposal by Ross Cameron (2008) and argue that the world as a whole can make all negative truths true, despite an apparent inconsistency in and an implausible consequence of Cameron's account. The discussion reveals how negative truths are grounded in reality on the basis of a reassessment of how such truths matter to truthmaker theory.
\end{abstract}

Key words: truthmaker theory, negative truths, metaphysical grounding, the world

\section{Introduction-Truthmaker Theory and the Problem of Negative Truths}

It is a widespread view among realist philosophers that propositions are true in virtue of something in the world, or that truth depends on reality. On the basis of this intuitive idea, truthmaker theory formulates the so-called truthmaker principle:

(TMP) For any true proposition (belonging to a certain class $C$ ), there is an entity that makes it true.

* Japan Society for the Promotion of Science/Kyoto University

E-mail: naoaki.kitamura@gmail.com

This work was supported by JSPS KAKENHI Grant Number 12J05339 (Grant-in-Aid for JSPS Fellows). Portions of this work were presented at the workshop "The Metaphysics of Truthmakers and Trope Ontology: Reading Takeshi Akiba's From Truth to Being" at the 2014 annual autumn meeting of the Japan Association for Philosophy of Science, held at the University of Tokyo on November 1st, 2014. I am grateful to Associate Professor Takeshi Kanasugi, Ikuro Suzuki, Associate Professor Takeshi Akiba, and other participants of the workshop as well as the anonymous referees of this journal for their critical comments, which helped me to improve my manuscript. 
Although there has been much work on the nature of truthmaking and its theoretical use, the problem of negative (existential) truths remains unresolved: what makes true statements that say how things are not? What is distinctive of this problem is that it appears to threaten the very prospects of truthmaker theory in its entirety. According to some philosophers, the theory must be rejected since (1) if it is true at all, then all truths, including negative truths, have truthmakers, but (2) there are no truthmakers for negative truths. ${ }^{1}$

The main ground for the denial of the existence of truthmakers for negative truths is that to assign truthmakers to these truths commits us to some peculiar and metaphysically dubious entity or entities, such as negative states of affairs and absences, which seem to result from the reification of negativity. Various attempts to provide truthmakers for negative truths have been argued to be all unsatisfactory from an intuitive or theoretical point of view. ${ }^{2}$ The claim of the necessity of maximalism-the view that all (contingent or non-analytic) truths have truthmakers-is based on the fact that the intuition motivating truthmaker theory concerns (contingent or nonanalytic) truth in general. ${ }^{3}$ Notice that the core claim of truthmaker theory, namely (TMP), rests on the sweeping idea that truth depends on reality. If, the opponents argue, truthmaker theory embodies this intuition in terms of the very notion of truthmakers indicated by (TMP), truthmaker theorists cannot justify any form of non-maximalism, as such a restriction would be utterly arbitrary in consideration of the general applicability of the intuition regarding the dependence of truth on reality.

In this paper, I argue against both (1) and (2). In the first part of the paper, I discuss (1): I consider the relation between truthmaking and grounding, and argue that truthmaker theorists need not necessarily embrace maximalism because, pace some opponents of the theory, the intuition of the dependence of truth on reality that is supposed to motivate truthmaker theory is independent of the truth of both maximalism and non-maximalism. This discussion enables me to reassess how negative truths matter to truthmaker theory and to emphasize the significance of providing ontological grounding for negative truths. Based on this reassessment, in the second part of the paper I deal with (2): I critically examine the proposal by Cameron (2008) and argue that the world as a whole can play the role of the truthmaker for all negative truths. To vindicate this claim, I explain away the alleged inconsistency in Cameron's account, and show how to accommodate, in a much more plausible way than Cameron's account, de re modal claims about the world as a whole. My approach to the problem of negative truths will yield a novel understanding of how negative truths are grounded in reality-how "what is not" (to mê eon) can be ap-

${ }^{1}$ See, especially, Dodd (2007).

${ }^{2}$ For an extensive discussion of why the alleged truthmakers for negative truths that have been proposed in the literature are all untenable, see Dodd (2007), pp.386-393.

${ }^{3}$ See Dodd (2007), pp.393-394. 
prehended on the basis of "what is" (to eon) ${ }^{4}$

Throughout this paper, I assume Truthmaker Necessitarianism, a common assumption that truthmaking entails necessitation: if $X$ is a truthmaker for $\langle P\rangle$, then as a matter of metaphysical necessity, $\langle P\rangle$ is true if $X$ exists. ${ }^{5}$

\section{The Possibility of Truthmaker Non-Maximalism}

\subsection{Truth-Functions and the Logical Validity-Criticizing Akiba's Argu- ment against Maximalism}

Akiba (2011) argues against (1) by claiming that maximalism must be rejected and hence that, quite contrary to the opponents' claim, truthmaker theorists must be non-maximalists. According to him, maximalism has difficulty in accommodating a standard understanding of truth-functions: "if we accept maximalism, we become unable to affirm the logical validity that we should think certain inferences containing some logical constant have." 6

Before examining this claim in detail, notice that it is an indirect argument against (1). As opponents derive (1) from the claim that non-maximalism must be rejected, the most straightforward and direct argument against (1) would consist of pointing out that non-maximalism is a viable position; this is sufficient to reject (1). However, Akiba argues for the stronger thesis that non-maximalism is not only viable but it is the only option for truthmaker theorists, claiming that the other position is unavailable.

Although Akiba focuses his attention on the necessity of non-maximalism rather than its possibility, he also makes, at the end of his paper, a brief remark on how we can embrace non-maximalism consistently in the first place, by way of a reply to the objection that non-maximalism must be rejected. ${ }^{7}$ His response consists of claiming that to give a theoretical formulation in terms of the notion of truthmakers to the intuition concerning the dependence of truth on reality does not, contrary to the objection, force us to embrace maximalism. According to him, truthmaker theorists can embody the intuition concerning the dependence in question not by the notion of having a truthmaker, but by the notion of "having an explanation that can be more or less directly traced back to the existence of some truthmaker(s)." 8 For example, he believes, truthmaker theorists can maintain that a true proposition, $\langle P \vee Q\rangle$, depends for its truth on reality not in the sense that this proposition has a truthmaker, but in

\footnotetext{
${ }^{4}$ Cf. Parmenides, On Nature, fr. 2.

${ }^{5}$ Angled brackets are conventionally used to form names of propositions: $\langle P\rangle$ stands for the proposition that $P$.

6 Akiba (2011), p.125, my translation.

7 Akiba (2011), pp.129-131.

8 Akiba (2011), p.130, my translation.
} 
the sense that its truth can be ultimately explained on the basis of the atomic truths composing $\langle P \vee Q\rangle$ that have truthmakers. To admit that the dependence of truth on reality may be indirect in this way does not, he argues, deprives the substance of the intuition concerning the dependence of truth on reality, as indirect dependence in question is still dependence on reality.

Thus, by discriminating direct dependence and indirect dependence, Akiba suggests that truthmaker theorists can restrict the truthmaker principle to atomic truths while respecting the general applicability of intuition concerning the dependence of truth on reality on which they base the truthmaker principle. Such a suggestion, however, has obvious problems concerning a specific class of complex truths, namely negative truths. Notice that negative truths differ from true conjunctions and disjunctions in that no entities correspond to the components of negative truths because these components are false. This situation makes it impossible to explain the truth of $\langle\neg P\rangle$ on the basis of the existence of the truthmaker for $\langle P\rangle$, because none exist. Akiba might object that truthmaker theorists can invoke not only the existence of the truthmakers for the components of a complex proposition, but also the nonexistence of such entities. This move, however, is illegitimate: he cannot maintain that the truth of $\langle\neg P\rangle$ is ultimately explained by the nonexistence of the truthmaker for $\langle P\rangle$, because its nonexistence is itself another negative proposition, namely that there are no truthmakers for $\langle P\rangle$, and as such, it requires further explanation in the same way as $\langle\neg P\rangle$ does. Thus, the invocation of nonexistence leads to an unending chain of explanation.

Akiba's response to the claim that non-maximalism must be rejected is, therefore, unsuccessful. To make matters worse, I claim, Akiba's main contention that maximalism has difficulty in accommodating a standard understanding of truth-functions is not correct either. Akiba considers the following two (schemata of) inferences containing a logical constant:

(C) $\langle P\rangle$ is true and $\langle Q\rangle$ is true $\Rightarrow\langle P \wedge Q\rangle$ is true.

(N) $\langle P\rangle$ is not true $\Rightarrow\langle\neg P\rangle$ is true.

As Akiba states, our understating of conjunction and negation as truth-functions partly consists in the affirmation of the logical validity of $(\mathrm{C})$ and $(\mathrm{N})$. In other words, "when the antecedent of $(\mathrm{C})[/(\mathrm{N})]$ obtains, the obtainment of its consequent is unconditionally ensured irrespective of how the world actually is in other respects." 9 However, according to Akiba, maximalism makes us unable to affirm that (C) and $(\mathrm{N})$ are valid in this sense - therefore, maximalism must be rejected. Let us examine, in turn, how maximalists have to understand $(\mathrm{C})$ and $(\mathrm{N})$.

Given maximalism, the antecedent and the consequent of $(\mathrm{C})$ consist in $\left(\mathrm{C}_{1}\right)$ and

\footnotetext{
${ }^{9}$ Akiba (2011), p.124, emphasis in original, my translation.
} 
$\left(\mathrm{C}_{2}\right)$ below, respectively:

$\left(\mathbf{C}_{1}\right)$ There exists an entity $e_{1}$ such that $e_{1}$ makes $\langle P\rangle$ true, and there exists an entity $e_{2}$ such that $e_{2}$ makes $\langle Q\rangle$ true.

$\left(\mathbf{C}_{2}\right)$ There exists an entity $e$ such that $e$ makes $\langle P \wedge Q\rangle$ true.

Maximalism, therefore, entails that the validity of (C) depends on that of " $\left(\mathrm{C}_{1}\right) \Rightarrow\left(\mathrm{C}_{2}\right)$." However, according to Akiba, "letting the validity of $(\mathrm{C})$ depend on such a principle amounts to abandoning the idea that $(\mathrm{C})$ is a logically valid inference," 10 because " $\left(\mathrm{C}_{1}\right) \Rightarrow\left(\mathrm{C}_{2}\right)$ " is a substantive metaphysical thesis about what exists, and hence the obtainment of its consequent is not unconditionally ensured when its antecedent obtains, unlike in the case of $(\mathrm{C})$.

Similarly, given maximalism, the antecedent and the consequent of $(\mathrm{N})$ consist in $\left(\mathrm{N}_{1}\right)$ and $\left(\mathrm{N}_{2}\right)$ below, respectively:

$\left(\mathbf{N}_{1}\right)$ For any entity $e$, it is not the case that $e$ makes $\langle P\rangle$ true.

$\left(\mathbf{N}_{2}\right)$ There exists an entity $e$ such that $e$ makes $\langle\neg P\rangle$ true.

Maximalism, therefore, entails that the validity of $(\mathrm{N})$ depends on that of " $\left(\mathrm{N}_{1}\right) \Rightarrow\left(\mathrm{N}_{2}\right)$." However, Akiba claims that this conditional is, again, a substantive metaphysical thesis about what exists-hence, maximalism has to reject the logical validity of $(\mathrm{N})$.

I claim that maximalists can counter both of these arguments. As for the case of conjunction, they can simply revise the truthmaker principle in terms of plural quantification (with a suitable revision of Truthmaker Necessitarianism) as follows:

(TMP*) For any true proposition (belonging to a certain class $C$ ), there is a plurality of entities that collectively make it true. ${ }^{11}$

Given $\left(\mathrm{TMP}^{*}\right)$ in addition to maximalism, the antecedent and the consequent of $(\mathrm{C})$ consist in $\left(\mathrm{C}_{1}{ }^{*}\right)$ and $\left(\mathrm{C}_{2}{ }^{*}\right)$ below respectively:

$\left(\mathbf{C}_{1}{ }^{*}\right)$ There exists a plurality of entities that collectively make $\langle P\rangle$ true, and there exists a plurality of entities that collectively make $\langle Q\rangle$ true.

$\left(\mathbf{C}_{2}{ }^{*}\right)$ There exists a plurality of entities that collectively make $\langle P \wedge Q\rangle$ true.

With the help of the revision of (TMP), therefore, maximalism entails that the validity of $(\mathrm{C})$ depends on that of " $\left(\mathrm{C}_{1}{ }^{*}\right) \Rightarrow\left(\mathrm{C}_{2}{ }^{*}\right)$." Notice that this conditional does not represent any substantial metaphysical principle about what exists, because any pair of pluralities of entities one of which collectively make $\langle P\rangle$ true and the other

${ }^{10}$ Akiba (2011), p.125, my translation.

${ }^{11}$ Sakon and Kajimoto (2012) seem to presuppose (TMP*); see Akiba (2014). I will follow the standard convention of using "plurality" in a liberal sense, counting not only genuine pluralities but also single objects as pluralities. 
of which collectively make $\langle Q\rangle$ true unconditionally constitutes a plurality of entities that collectively make $\langle P \wedge Q\rangle$ true. Indeed, Akiba concedes that this might be an available option. ${ }^{12}$ The only further disagreement would be whether the position resulting from revising (TMP) as above would still constitute maximalism. I claim that the core idea in (TMP) is that the truth values of propositions are determined by facts about existence, and it is clearly inherited in (TMP*)-therefore, the revised formulation of the truthmaker principle does constitute maximalism.

As for the case of negation, notice first that $\left(\mathrm{N}_{1}\right)$ is equivalent to the following statement:

(E) There is no entity $e$ such that $e$ makes $\langle P\rangle$ true.

As this is a negative truth, it follows from maximalism that this truth consists in the following statement:

$\left(\mathbf{N}_{3}\right)$ There exists an entity $e$ such that $e$ makes $\langle E\rangle$ true.

Maximalism, therefore, entails that the validity of $(\mathrm{N})$ depends on that of " $\left(\mathrm{N}_{3}\right) \Rightarrow\left(\mathrm{N}_{2}\right)$." The crucial point is that this inference is logically valid if any entity that makes $\langle E\rangle$ true also makes, unconditionally, $\langle\neg P\rangle$ true, which is plausibly the case. Any entity that makes 〈There is no entity that makes 〈There are unicorns〉 true true, for example, would also makes 〈There are no unicorns〉 true; unicorns would surely make $\langle$ There are unicorns $\rangle$ true if existed, after all.

Thus, maximalists have no in-principle difficulty in affirming the logical validity of both $(\mathrm{C})$ and $(\mathrm{N})$.

\subsection{The Motivations for Truthmaker Theory Reconsidered}

Unlike Akiba, I do not claim that maximalism has any intolerable defect. Instead I claim that the sweeping intuition concerning the dependence of truth on reality does not, as such, support maximalism or non-maximalism because truthmaker theory does not in fact rest on this intuition in the way opponents suppose. In the rest of this section, I discuss how the notion of truthmaking is connected to the notion of grounding, and then reconsider exactly how the truthmaker principle "rests on" the general intuition in question.

\subsubsection{Truthmaking, Grounding, and Fundamentality}

As noted in $\$ 1$, truthmakers are supposed to be entities in virtue of which true propositions are true: they ground the truth of propositions. This intuitive characterization of truthmakers does not specifically differentiate "truthmaking" and "grounding." However, the former can in fact be defined in terms of the latter.

\footnotetext{
12 Akiba (2011), p.132, note 17.
} 
The first point to notice is that although both truthmaking and grounding have to do with metaphysical priority, the latter is the more general notion when compared to the former. Truthmaking concerns the priority of the existence of things over truth: the truth values of propositions are determined by what exists. In contrast, grounding concerns the priority relation among facts or (the contents of) true proposisiotns: a certain fact (e.g., a mental fact) holds in virtue of certain other facts (e.g., neurophysiological facts). Thus, in each case of truthmaking, the explandum is the truth of a true proposition, and the explanans is the existence of an entity, whereas grounding, as a relation among facts in general, semantic or non-semantic, existential or non-existential, does not exhibit such restrictions.

This leads us to consider the following definition, which some philosophers have proposed:

(Df $\mathbf{f}_{1}$ ) An entity $e$ makes $\langle P\rangle$ true.

$\stackrel{\text { def }}{\Longleftrightarrow}$ The fact that $e$ exists grounds the fact that $\langle P\rangle$ is true. ${ }^{13}$

This definition certainly gives a fairly straightforward understanding of truthmaking: in this definition, the truthmaking relation can be simply reduced to the grounding relation between the existence of an entity and the truth of a proposition.

However, $\left(\mathrm{Df}_{1}\right)$ has a defect. Note that $\left(\mathrm{Df}_{1}\right)$ allows for any entity that grounds the truth of a proposition to qualify as a truthmaker, irrespective of the metaphysical status of the entity has. According to $\left(\mathrm{Df}_{1}\right)$, a chair, for example, qualifies as a truthmaker for 〈There is a chair〉 even if its existence is not fundamental, i.e., its existence is grounded in another fact. This lack of discrimination deprives the notion of truthmakers of its theoretical significance. For this notion serves as the measure of the ontological commitment of a theory/sentence: a theory/sentence commits to the entities that are ultimately required to explain its truth. ${ }^{14}$ For example, "There is a chair" is not ontologically committed to a chair, but to the state of affairs of some aggregate of elementary particles being arranged chair-wise, if the existence of the former is ultimately explained by that of the latter.

Therefore, in order to keep the notion of truthmakers theoretically significant and metaphysically interesting, we should incorporate into it the notion of fundamentality. Taking this point into account, we can revise $\left(\mathrm{Df}_{1}\right)$ as follows:

$\left(\mathbf{D f}_{2}\right)$ An entity $e$ makes $\langle P\rangle$ true.

$\stackrel{\text { def }}{\Longleftrightarrow}$ The fact that $e$ exists grounds the fact that $\langle P\rangle$ is true and the existence of $e$ is not grounded in any fact.

That is, to claim that a proposition is made true by a certain entity is to claim that

\footnotetext{
13 See, for example, Correia (2005), §3.2.

${ }^{14}$ Cf. Cameron (2010).
} 
the existence of the entity grounds the truth of the proposition and that the former fact is fundamental.

\subsubsection{The Theoretical Status of the Truthmaker Principle}

This definition has an immediate implication regarding the theoretical status of the truthmaker principle. As noted above, this principle has been commonly associated with the intuition that truth depends on reality. The above definition, however, enables us to see that the principle cannot be taken as an uncontroversial consequence of this intuition, nor as its theoretical formulation or explication in terms of the notion of truthmakers. It should instead be understood as a fairly substantive and controversial metaphysical claim about what the fundamental aspect of reality is like. To claim that, for example, predicational truths of the form $\langle a$ is $F\rangle$ have truthmakers is to claim that every truth of this form is not ultimately explained by the fact that $a$ is $F$, but by a fundamental existential fact (e.g., the existence of the state of affairs of $a$ being $F$ ). This amounts to the claim that property instantiation is not a fundamental aspect of reality but a derivative one explained by or reduced to what exists. Similarly, to claim that propositions of the form 〈There are no $X \mathrm{~s}$ ) and of $\langle$ There were $X \mathrm{~s}\rangle$ have truthmakers is to claim that negation and tense represent derivative aspects of reality explained by or reduced to what exists. Thus, the truthmaker principle, whether it is stated in the unrestricted form or in some restricted form, cannot in fact qualify as a "principle" that is pre-theoretically justified. Note that this does not force us to reject any claims of truthmaking from the outset. Rather, the question of which propositions have truthmakers (i.e., whether predication, negation, tense, and so on represent the fundamental aspect of reality) must be determined on a case-by-case basis through substantive metaphysical investigations.

Truthmaker theory, therefore, does not in fact rest on the intuition that truth depends on reality in the way its opponents suppose. Of course, truthmaker theorists do not deny this intuition, and some of them may actually take the truthmaker principle to be a theoretical formulation or explication of this intuition in terms of the notion of truthmaking. However, given that the notion of truthmaking should be understood as defined in $\left(\mathrm{Df}_{2}\right)$, the truthmaker principle cannot be thought of as such a formulation or explication. It is a substantive and controversial metaphysical claim that must be argued for/against through investigations on the nature of fundamental reality, not just by cashing out any intuition in terms of any theoretical notion. In other words, the intuition concerning the dependence of truth on reality and the truthmaker principle are not related in such a way that the latter must inherit the general applicability to all truths from the former. Thus, the intuition in question-though truthmaker theorists have to accept it-does not, as such, support maximalism or non-maximalism, and truthmaker theorists need not necessarily embrace the former. 


\subsection{Reassessing the Problem of Negative Truths}

The discussion so far contributes to reassessing how negative truths matter to truthmaker theory and to appreciating the significance of providing ontological grounding for negative truths.

Opponents of truthmaker theory believe that the difficulties of providing truthmakers for negative truths undermines truthmaker theory. I have discussed why that is not true. Truthmaker theory does not have to be abandoned if we cannot provide truthmakers for negative truths, because truthmaker theorists need not necessarily embrace maximalism - they may well advocate the view that negation represents a fundamental aspect of reality, unexplainable by existential facts. Thus, negative truths do not make any devastating problem for truthmaker theory. In short, there is no such thing as "the problem of negative truths" in the way that opponents think of it.

Negative truths, however, are still a problem worth taking seriously - or rather, they produce an explanatory project worth pursuing. If negation represents a fundamental aspect of reality, fundamental negative facts abound. Specifically, many negative existential facts such as (There are no unicorns) and (There are no talking donkeys $>$ would be fundamental. By contrast, if negative facts have truthmakers and hence all these negative facts can be ultimately explained by existential facts, we can get a more simple and parsimonious theory about reality. In particular, if we can provide all negative truths with one and the same truthmaker, the great parsimony will be achieved - many fundamental negative facts are ultimately explained by just one fundamental existential fact. Even a theory that assigns each negative fact a sui generis truthmaker, such as the absence of unicorns and the absence of talking donkeys, would be qualitatively parsimonious. We do not need negation to "write the book of the world," after all. ${ }^{15}$

Thus, it is worth seeking a successful strategy for providing ontological grounding for negative truths. It is such an explanatory project that I will pursue in the rest of this paper. Indeed, I defend a demanding view according to which all negative truths have one and the same truthmaker.

\section{The World as the Ontological Ground for Negative Truths}

\subsection{Cameron on the Nature of the World}

Ross Cameron offers a novel solution to the problem of negative truths. According to him, all negative truths are made true by one and the same entity, the actual world. ${ }^{16}$

\footnotetext{
${ }^{15}$ Cf. Sider (2011).
}

16 Cameron (2008). Strictly speaking, it is sufficient to provide the truthmaker(s) for all true negative existentials in order for us to solve the problem of negative truths. 
Let me reconstruct Cameron's argument. The argument has two crucial premises. The first is the following claim about the individuation of concrete worlds: (IndW) For any two possible worlds $w$ and $v$, the concrete world (the sum of all concreta) in $w$ and that in $v$ are identical if and only if all and only the propositions that are true in $w$ are true in $v$.

This principle entails that there are no transworld identities between concrete worlds in distinct possible worlds, since for any pair of distinct possible worlds, there has to be some proposition that is true at only one of these two worlds. In particular, the actual world, the sum of all concrete entities that actually exist, is individuated by what is actually true, and does not bear the relation of transworld identity to the concrete world in $w$, for any merely possible world $w^{17}$

The second crucial premise of Cameron's argument is the following claim about the essential maximality of concrete worlds:

(MaxW) For any possible world $w$, the concrete world in $w$ is essentially the maximal sum of concrete entities.

In other words, "[t]he world is the biggest thing. It is a world because there is nothing bigger than it that it is a proper part of." 18 (MaxW) excludes any proper part of the concrete world in $w$ from representing a way the concrete world in $v$ could have been, for any possible worlds $w$ and $v$. Consequently, no proper part of the concrete world in $w$ bears the relation of transworld identity to the actual world, for any possible world $w$. Even a duplicate of the actual world cannot, if it is a proper part of some other concrete entity.

Thus, (IndW) and (MaxW) jointly entail that nothing in merely possible worlds bears the relation of transworld identity to the actual world. This amounts to the claim that the actual world has all its properties essentially. It follows from this that

(NecN) For any actually true negative proposition $P$, the actual world is essentially such that $P$ is true.

That is, the truth of any actually true negative proposition is ensured by the nature of the actual world, being necessitated by the existence of the actual world. We can therefore regard the actual world as the truthmaker for all negative truths.

Note that there is no obvious problem with Cameron's proposal as far as the existence of actual world is concerned: it is just a mereological sum of concrete entities, albeit a maximal one. It is not problematic to admit such a sum in ontology if

For, as Cameron says, "to account for the truth of $\neg p$ we need only point to the truthmaker for 〈there is no truthmaker for $p\rangle$ " (p.411).

${ }^{17}$ Cameron himself employs counterpart-theoretic talk. See note 9 in Cameron (2008).

${ }^{18}$ Cameron (2008), p.417. 
we accept the existence of other ordinary concrete sums such as molecules, cats, and planets. ${ }^{19}$

Cameron's main aim is to establish that the actual world serves as the truthmaker for negative truths, but it appears that his argument establishes also that the actual world serves as the truthmaker for all truths, both positive and negative. This is because (IndW) and (MaxW) seem to establish a stronger thesis than (NecN). As we have seen, Cameron's two main claims jointly entail that nothing in merely possible worlds worlds bears the relation of transworld identity to the actual world, and this amounts to the claim that the actual world has all its properties essentially. However, it follows from this that

(Nec) For any actually true proposition $P$, the actual world is essentially such that $P$ is true.

Accordingly, Cameron's account appears to amount to truthmaker monism, the thesis that there is only one truthmaker, which seems to trivialize truthmaker theory. Cameron responds to this possible objection that "while the world is a suitable truthmaker for negative exsitentials it is not a suitable truthmaker for propositions of the form $\langle a$ is $F\rangle, "{ }^{20}$ and explicates the unsuitability in question in terms of the dependence of the actual world on its parts for its existence: "the world is the very world it is in virtue of its constituents; were the world to be constituted differently, it would not be the very world it in fact is." ${ }^{21}$ That is, the actual world is not a suitable truthmaker for positive truths because the actual world existentially depends on its proper parts, and the existence of these proper parts are sufficient to ground positive truths. By contrast, no proper part of of the actual world correspond to any negative truth. Hence, in spite of dependence in question, we can still think of the actual world as the truthmaker for negative truths.

\subsection{Full Ground and Partial Ground-How to Avoid the Inconsistency with Necessitarianism}

\subsubsection{Worlds as Dependent Objects and Necessitarianism}

I will first consider whether Cameron's characterization of the nature of concrete

${ }^{19}$ Cameron himself does not claim the advantage of his own account by arguing for the peculiarity of entities such as negative states of affairs and absences, or for the intuitive plausibility of his characterization of the actual world. The advantage he cites concerns the (weaker version of) Humean denial of necessary connections between distinct entities. Although his argument is interesting, I shall not make inquiry into Cameron's own point; to do so would involve us in a discussion of the Humean dinaial of necessary connections, which deserves an extensive and detailed examination, and would take us beyond the scope of the present paper.

20 Cameron (2008), p.418.

21 Cameron (2008), p.418. 
worlds is consistent with a certain plausible principle of grounding.

As described above, Cameron characterizes (concrete) worlds as dependent objects: a world is the very world that it is in virtue of its constituents. This dependence, like truthmaking, can be naturally formulated in terms of grounding as follows:

$\left(\mathbf{D f}_{3}\right) x$ existentially depends on $y \stackrel{\text { def }}{\Longleftrightarrow}$ Some fact about $y$ grounds the fact that $x$ exists. $^{22}$

The facts about the constituents of a world relevant to grounding plausibly include the existence of these constituents. That is, for any concrete world $W$, the fact that the constituents of $W$ exist grounds the fact that $W$ exists. More specifically,

(Dep) The fact that the actual concreta exist grounds the fact that the actual world exists.

However, (Dep) and (MaxW) together seem to be inconsistent with a plausible principle concerning the connection between grounding and modality, namely Ground Necessitarianism: for any facts $f$ and $g$, if $f$ is grounded in $g$, then as a matter of metaphysical necessity, $f$ obtains if $g$ obtains. This is for the reason that (Dep) and Ground Necessitarianism together entail that

(Suf) For any possible world $w$, if all the actually existing concreta exist in $w$, then the actual world exists.

At the same time, $(\mathrm{MaxW})$ entails, as described above, that the possible concrete world composed of all the actually existing concreta plus unicorns does not bear the relation of transworld identity to the actual world: the actual world does not exist in such a world. This contradicts (Suf).

Thus, the proponents of Cameron's account seem to be presented with an intolerable dilemma: either give up at least one of (MaxW) and (Dep), or reject Ground Necessitarianism. They cannot opt for the first horn without drastically revising their view, since both theses are essential to Cameron's strategy for providing ontological grounding for negative truths: (MaxW), combined with (IndW), entails $(\mathrm{NecN})$, which enables us to regard the actual world as the truthmaker for all negative truths; (Dep) prevents the whole-world truthmaker strategy from collapsing into truthmaker monism. The second horn is highly problematic too because Ground Necessitarianism constitute a key assumption about the nature of grounding. As such, the rejection of Ground Necessitarianism requires independent reason other than the apparent inconsistency with Cameron's account. ${ }^{23}$

\footnotetext{
${ }^{22}$ Cf. Correia and Schnieder (2012), pp.24-25.

${ }^{23}$ Notably, Griffith (2012) doutbts the consistency of Cameron's account (note 3), 
I claim that this inconsistency is only apparent, not real. The crucial point is that (Suf) does not follow from (Dep) and Ground Necessitarianism once we differentiate between two different senses of "ground" in the latter two theses. Ground Necessitarianism is intended to involve the concept of full ground: when $f$ is fully grounded in $g$, describing $g$ is sufficient to metaphysically explain $f$. The idea of necessitation involved in Ground Necessitarianism amounts to this notion of sufficiency. By contrast, (Dep) can be construed as involving the concept of partial ground: when $f$ is at least partially grounded in $g$, describing $g$ may not be sufficient, but goes some way towards metaphysically explain $f$. Partial grounding may not entail necessitation. The existence of the set $\{$ Plato, Aristotle\}, for example, is only partly, but not fully, grounded in the existence of Aristotle; hence it is possible that Aristotle exists without the set existing. ${ }^{24}$ Accordingly, the proponents of Cameron's account can maintain that the existence of the actual world is only partly, not fully, grounded in the existence of the actual concreta, and hence that (Dep) does not, in conjunction with Ground Necessitarianism, entail (Suf).

\subsubsection{Dependence and Fundamentality}

Explaining away the alleged inconsistency in Cameron's account in this way might prompt the following question: if the existence of the world is only partially grounded in the existence of its components, what on earth fully grounds it?

The proponents of Cameron's account can reply that nothing fully grounds the existence of the world. However, it might be objected that this move is illegitimate because it is difficult to see how an object can be both dependent and fundamental, that is, how an object's existence can be partly grounded in certain facts without there being anything that fully grounds it. There is though nothing in-principle wrong with the move as some philosophical doctrines can plausibly admit this combination of dependence and fundamentality. For instance, consider Timothy Williamson's "knowledge first" view. According to him, knowledge cannot be analyzed in terms

though he does not make the assumption of Ground Necessitarianism explicit. In fact, his main contention is that Cameron's account suffers from the serious explanatory deficiency that the actual world cannot qualify as grounding negative truths given its existence condition. Griffith takes this (alleged) deficiency to exemplify a general pattern of failure in providing ontological grounding for negative truths. Although his argument is worth careful examination, this would lead us to issues about the nature of metaphysical explanation more generally, and as such, it is beyond the purposes of this paper. For a counterargument against Griffith, see Kitamura (2014).

${ }^{24}$ For the distinction between full ground and partial ground, see, for example, Correia and Schnieder (2012), p.20. Note that the legitimacy of this distinction is a shared assumption in the literature. Accordingly, the invocation of the distinction here does not constitute a substantial and controversial claim. I thank an anonymous referee for pressing me to clarify this point. 
of other, more fundamental epistemic notions. ${ }^{25}$ Thus Williamson argues that, on the one hand, knowledge is a sui generis mental state, and hence he is committed to the idea that facts about knowledge are not fully grounded in any other facts. On the other hand, however, he emphasizes that the "knowledge first" project is consistent with the traditional idea that truth, belief, and justification are all necessary elements for knowledge. Hence, given that "necessary condition" in this context can be reformulated in terms of the notion of ground, Williamson acknowledges that, for example, the fact that $S$ knows that $P$ is partly grounded in the fact that $P$. Alternatively, consider the doctrine that there are emergent properties: the proponents of this doctrine (or at least, those who advocate what is sometimes called "ontological emergence") often claim that although emergent properties are in some sense dependent on the base properties from which they emerge, they are nevertheless basic or fundamental in that they are "genuinely novel" or "over and above" the base, not being determined by it. ${ }^{26}$ Some philosophers have felt uncertain about whether emergence is intelligible. It seems to me, however, that this uncertainty is due to confusing the distinction between full ground and partial ground which seemingly leads to contradiction: once we construe the dependence of emergent properties as being only partially grounded in the base properties, and the fundamentality of emergent properties as not being fully grounded in those properties, the situation becomes similar to that of the "knowledge first" view; and the feeling of uncertainty will most likely disappear. To be sure, it is controversial whether the "knowledge first" view is tenable and whether there really are emergent properties, but insofar as these views are intelligible, we can consistently deny full ground to the existence of the world.

Furthermore, as it turns out, the move in question is not only legitimate, but also inevitable. There are two reasons for this. First, it is inevitable because of the definition of truthmaking in terms of grounding. I defined truthmakers in $\S 2.2 .1$ as follows:

$\left(\mathbf{D f}_{2}\right)$ An entity $e$ makes $\langle P\rangle$ true.

$\stackrel{\text { def }}{\Longleftrightarrow}$ The fact that $e$ exists grounds the fact that $\langle P\rangle$ is true and the existence of $e$ is not grounded in any fact.

Recall that the latter necessary condition in the definition embodies the idea that truthmakers are primitive, ultimate entities required to explain the truth of a certain theory or sentences. In other words, truthmakers are indispensable to "write the book of the world." We can formulate this indispensability more precisely in terms of the notion of the lack of full ground, but not that of the lack of partial ground; an entity whose existence is only partially grounded is still needed to give the complete

\footnotetext{
${ }^{25}$ Williamson (2000).

${ }^{26}$ See, for example, O'Connor and Wong (2005).
} 
description of the world. Thus $\left(\mathrm{Df}_{2}\right)$ can be revised as follows:

$\left(\mathbf{D f}_{4}\right)$ An entity $e$ makes $\langle P\rangle$ true.

$\stackrel{\text { def }}{\Longleftrightarrow}$ The fact that $e$ exists grounds the fact that $\langle P\rangle$ is true and the existence of $e$ is not fully grounded in any fact.

Given the revised definition, the proponents of the whole-world strategy ought to hold that nothing fully grounds the existence of the world: truthmakers lack full ground by definition.

Second, even if the proponents of Cameron's account do not adopt my definition of truthmaking, hence allowing an entity whose existence is fully grounded to be a truthmaker, the move in question is still inevitable because of the unavailability of any fact that, in conjunction with the existence of the components of the world, would fully ground the existence of the world. Suppose that the existence of the world is fully grounded in the fact $f$ in conjunction with the existence of the components of the world. On the one hand, truthmaker theorists cannot maintain that $f$ is a nonexistential fact, such as that the actual concreta compose the world, because the core idea in truthmaker theory is, as noted in $\S 2.1$, that the truth values of propositions are determined by facts about existence; to invoke a non-existential fact in order to provide grounding for negative truths is to abandon providing ontological grounding for these truths. In effect, this is to abandon the claim that negative truths have truthmakers. On the other hand, $f$ cannot be an existential fact, because the world is the sum of all concreta, and there is no other concrete object whose existence would be identified with $f$. Given that abstract objects are irrelevant to the grounding of contingent truths concerning physical reality, no existential fact, besides the existence of the actual components of the world, is available for the proponents of Cameron's account.

\subsection{De Re Modal Properties of the World}

\subsubsection{Does the World Necessarily Lack Unicorns?}

The second objection against Cameron's account that I shall consider concerns the ways that the actual world could have been. (NecN) amounts to the claim that the actual world is necessarily such that $P$ is true, for any actually true negative proposition $P$; the actual world could not have been such that, for instance, (There are talking donkeys $\rangle$ is true. This line of reasoning seems to collide head-on with the intuitively true claim that the actual world could have been such that talking donkeys existed. The same holds for all other intuitively true negative claims. Thus $(\mathrm{NecN})$ seems to have an extremely counterintuitive consequence about how the actual world could have been. This is the immediate objection that will most naturally arise to 
$(\mathrm{NecN}) \cdot{ }^{27}$

Cameron thinks that the distinction between modality de dicto and de re enables us to see that the apparent problem is not real one: the intuitively true de re modal claim that the actual world could have included talking donkeys is, contrary to appearance, the true de dicto claim that talking donkeys are possible. From the fact that there is a possible world $w$ in which there are talking donkeys, it does not follow that $w$ represents a way that the actual world, the maximal sum of concrete entities, could have been. Nor does it follow, from the fact (according to $(\mathrm{NecN})$ ) that the actual world could not have included talking donkeys, that there is no possible world in which there are talking donkeys. The collision of ( $\mathrm{NecN})$ with our modal intuition, he believes, can therefore be avoided. ${ }^{28}$

Cameron's response is coherent, but unsatisfactory. It remains unclear why we can interpret all the apparently de re modal claims about the actual world as de dicto modal claims. To do so would be to regard a certain range of modal discourse as being systematically disguised in a grossly misleading way: sentences of the form "The actual world could have been such that $P$ " would not be a literally true de re modal claim. It is difficult to see what about the maximal sum of actual concreta can justify such a general claim.

\subsubsection{Two Distinct Maximal Sums of All Concreta}

I offer a crucially different response: the phrase "the actual world" occurring in intuitively true modal sentences does refer rigidly to $a$ maximal sum of actual concrete entities, but this sum is different from the one for which Cameron provides a distinctive criterion of transworld identity by (IndW) and (MaxW). In other words, I claim that there are in fact two maximal sums of actual concrete entities, one of which is what Cameron calls "the actual world," and the other of which is the entity that the intuitively true modal sentences with the grammatical subject "the actual world" are about. In the following discussion, I continue to use the phrase "the actual world" in the same way as Cameron, while I introduce "the World" with a capital "W" for the referent of the grammatical subjects of the intuitively true modal sentences in question. If the actual world and the World are distinct entities, the distinction enables us to catch two hares at once: we can provide the truthmaker for negative truths by accepting Cameron's account resulting from (IndW) and (MaxW), and we can avoid the collision of the account with our modal intuition, not regarding intuitively true modal sentences with the grammatical subject "the actual world" as literally false. These sentences can now be interpreted-taking them at face value-as expressing

${ }^{27}$ Akiba (2011) raises such an objection (pp.126-129), although the theory that Akiba's argument directly attacks (what he calls the "type-W maximalism") is truthmaker monism, not Cameron's position.

${ }^{28}$ Cameron (2008), p.413. 
propositions about the World.

The key to make the distinction between the actual world and the World is to think that the actual world constitutes the World, just as a lump of clay constitutes a statue. Clearly, the actual world and the World are related in such a way as to satisfy two necessary conditions for constitution, spatial coincidence and material coincidence. It is commonly assumed by constitution theorists that constituting and constituted entities share the same spatial location and the same parts. In the case of the actual world and the World, the shared spatial location is all of space, and the shared parts are all actual concrete entities.

Note that the constitution relation invoked here must be of the kind characterized by the so-called constitution view. The core claim made by defenders of the constitution view is that constitution is not identity: the clay statue is a distinct entity from the lump of clay that constitutes it. Similarly, the World is a distinct entity from the actual world that constitutes it. The idea that constitution is not identity follows from the commonsensical assumption that constituting and constituted entities differ with respect to their noncategorical properties. Suppose a lump of clay had existed before a statue was constituted by it at $t$. As the lump existed at $t$ while the statue did not, the two entities differ with respect to their temporal properties. The noncategorical properties in question also include de re modal properties: a statue could have been, for example, composed of somewhat different parts, while the particular lump of clay that constitutes it could not. Similarly, the World and the actual world differ with respect to their de re modal properties: the World could have been composed such that, for example, it included talking donkeys, while the actual world that constitutes it could not.

I claim that there is no serious problem-intuitive or theoretical-with the proposed distinction between the actual world and the World. There are two reasons for this claim.

First, the assumption of the existence of the World, along with its de re modal properties like "possibly such that there are talking donkeys," can be considered as a pretheoretical datum. No de dicto modal statement is about any particular ordinary individual, to be sure, but every such statement is about things in general. We may call this subject matter, which is implicitly alluded to in each de dicto modal statement, the World. In this sense, the World is "the comprehensive subject of possibility of modality de dicto," 29 and every de dicto modal statement trivially qualifies as a de re modal statement about it. When we say that it is possibly (or necessarily) the case that $P$, for any $P$, we are saying that the World is such that a (or every) possible world that $P$, which is in turn equivalent to the statement that the World is such that possibly (or necessarily) $P$. In this sense, the commitment to the existence

\footnotetext{
29 Yagisawa (2010), p.45.
} 
of the World, along with its de re modal properties, represents nothing beyond our pretheoretical commitment to de dicto modality in general.

Second, the relationship between the actual world and the World--as I have construed it-is simply an instance of a ubiquitous relationship, namely constitution. As L. R. Baker says, "[c]onstitution is everywhere: pieces of paper constitute dollar bills; pieces of cloth constitute flags; pieces of bronze constitute statues ... strands of DNA constitute genes." 30 Baker herself regards constitution as also applying to persons and bodies, but I have regarded it as applying to the actual world and the World as well. The distinctive feature of these entities is their mereological inclusiveness: they are the biggest things of which all actual concreta are a part. The pervasiveness of constitution, nevertheless, should ensure that the appeal to the concept in the present case does not provoke any incredulity.

One might argue that the constitution view, which is needed to distinguish the actual world and the World, faces serious objections, including the extensionality objection, as the constitution view denies the extensionality of parthood, and the grounding objection, as there seems to be no ground for differentiating the noncategorical properties of constituting and constituted entities. Other accounts of the problem of material constitution include the view that constitution is identity, which might suggest that there is no such distinction as I am proposing to apply to the actual world and the World. I will not defend the constitution view in the present paper. Instead, I will simply stress the fact that the constitution view is an extremely popular view, and that most metaphysicians consider it to be intuitively plausible to a large extent, although not theoretically impeccable. My reasoning assumes the legitimacy of the constitution view, and the difficulties besetting the latter beset the former as well. Nevertheless, the intuitive plausibility and the status of the standard account of the constitution view can be regarded as supporting my method. Alternatively, we may restrict the scope of the constitution view to only the relationship between the actual world and the World, taking it as the limit case of constitution; there is no need to rely on the constitution view in its entirety to provide a solution to the problem of negative truth through my preferred reasoning.

\section{Conclusion}

We have seen that a Cameronean solution for the problem of negative truths can be developed in such a way that its apparent inconsistency and implausible consequence are avoided. The actual world, a maximal sum of all concreta, makes all negative truths true. The import of this result cannot be overemphasized: the claim that negative truths have a truthmaker does not mean that the intuition that truth

\footnotetext{
${ }^{30}$ Baker (2000), p.21.
} 
depends on reality can be embodied in terms of the notion of truthmakers in its full generality; rather, it amounts to a substantive metaphysical claim about fundamental reality, namely that negation represents a derivative aspect of reality that is ultimately explained by a fact about existence.

\section{References}

Akiba, T. (2011), "Why Should the Truthmaker Principle Be Restricted?" (In Japanese), Kagaku Tetsugaku 44(2): 115-134.

Akiba, T. (2014), "The Truthmaker Principle and Maximalism Reconsidered" (In Japanese), Kagaku Tetsugaku 47(1): 83-84.

Baker, L. R. (2000), Persons and Bodies: A Constitution View, Cambridge: Cambridge University Press.

Cameron, R. P. (2008), "How to Be a Truthmaker Maximalist," Noûs 42(3): 410-421.

Cameron, R. P. (2010), "How to Have a Radically Minimal Ontology," Philosophical Studies 151(2): 249-264.

Correia, F. (2005), Existential Dependence and Cognate Notions, Munich: Philosophia Verlag.

Correia, F. and Schnieder, B. (2012), Metaphysical Grounding: Understanding the Structure of Reality, Cambridge: Cambridge University Press.

Dodd, J. (2007), "Negative Truths and Truthmaker Principles," Synthese 156(2): 383-401.

Griffith, A. M. (2012), "On Some Alleged Truthmakers for Negatives," Thought: A Journal of Philosophy 1(4): 301-308.

Kitamura, N. (2014), "Is Any Alleged Truthmaker for Negatives Explanatorily Deficient?" Thought: A Journal of Philosophy 3(3): 200-207.

O'Connor, T. and Wong, H. Y. (2005), "The Metaphysics of Emergence," Nô̂s 39(4): 658678.

Parmenides, On Nature, in H. Diels and W. Kranze (eds.) (1951-52), Die Fragmente der Vorsokratiker, 6th edition, Berlin: Weidmann.

Sakon, T. and Kajimoto, N. (2012), "Is the Restriction of the Truthmaker Principle Justified?" (In Japanese), Kagaku Tetsugaku 45(2): 131-134.

Sider, T. (2011), Writing the Book of the World, Oxford: Oxford University Press.

Willamson, T. (2000), Knowledge and its Limits, Oxford: Oxford University Press.

Yagisawa, T. (2010), Worlds and Individuals, Possible and Otherwise, Oxford: Oxford University Press.

(Received 2014.8.11; Revised 2015.2.1; Second Revised 2015.8.18; Accepted 2015.9.4) 